\title{
Graphic gropings
}

When a flash of inspiration strikes an inventor or a scientist pondering a theory, they scramble for a scrap of paper on which to capture the thought. When these jottings are drawings they become a form of graphic art.

\section{Martin Kemp}

$\mathrm{R}^{\mathrm{s}}$ ough sketches in a notebook, on a blackboard, or even on the back of the proverbial envelope have played central roles in scientific and technological creativity. The rapid act of graphic visualization, the 'thinking' doodle, the schematic thought experiment, the improvised diagram, the scribbled solution, are now familiar to us through the publication of scientists private papers. These informal fragments seem to bring us closer to the workings of the inventive mind. But it was not always so.

With a few exceptions - Leonardo da Vinci is the most notable example - informal graphic material has not been preserved from earlier eras of science. Some of it was on erasable surfaces, but, more importantly, it was not generally thought worthy of preservation, not least by the originators of the material themselves.

\section{Whereas artists' sketches had been collectable since the Renaissance, scientists' notebooks generally attracted little attention until the later part of nineteenth century, and those that did survive were preserved for reasons of archival piety rather than as precious records of inspiration, false starts, changes of mind and so on. The difference speaks of a substantial historical gulf in the attitudes towards creativity in art and science.}

It is now broadly accepted that informal jottings can provide fascinating insights into the varied nature of the processes of visualization in different kinds of scientific activity and in individual scientists' work. The private papers of two of the greatest visualizers, Thomas Edison and Henri Poincaré, show how spontaneous acts of notation on paper can service technological invention no less effectively than they can nourish mathematical theorizing.

Edison consciously projected his own image as a genius of invention - even if his famous "ninety-nine per cent perspiration" proved crucial to his commercial success. His Menlo Park 'invention factory' in New Jersey was set up as a crucible for his creative energies. He originated a remarkable string of patented devices there between 1876 and 1883 - an improved telephone, the phonograph, incandescent lighting and so on.

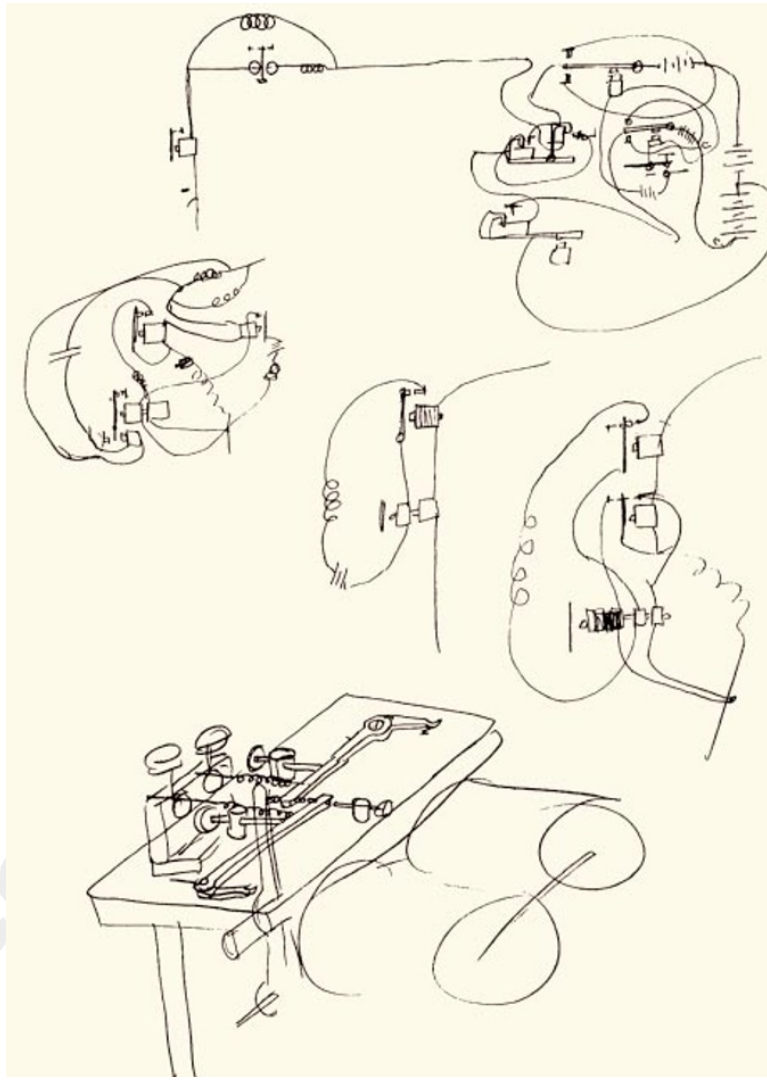

Sketches for a sextuplex set-up in multiple telegraphy, signed by Thomas Edison, James Adams and Charles Batchelor (10 April 1877).
The voluminous notes and drawings signed by Edison and his closest associates display an endless fertility in the conducting of thought experiments. Impulsive jottings of circuits, components, interconnections and new mechanisms, using a variety of graphic conventions, served serendipitous processes of invention, in which ideas could be tested, approved, refined or eliminated.

For his part, Poincaré, uniquely elected to all five sections of the French Academy of Sciences - geometry, mechanics, physics, geography and navigation - became the very model of mathematical creativity. This was exemplified particularly through his

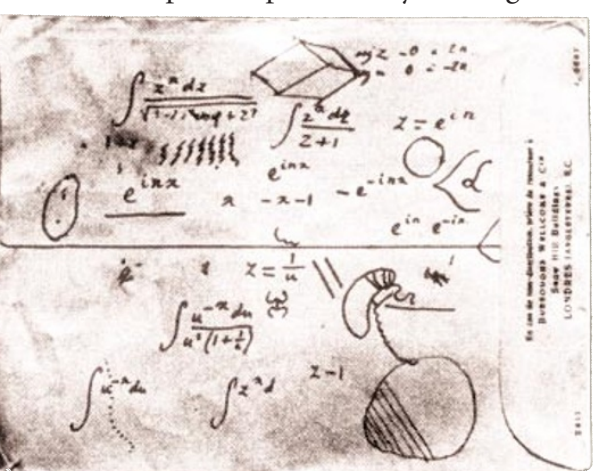

A back-of-the-envelope calculation by Henri Poincaré. own Science and Hypothesis in 1903 and through Edouard Toulouse's psychological study, published as Henri Poincaré in 1910. Poincaré lauded "intuition" as the key to his "ability to perceive the whole argument at a glance" and to determine where the "beauty" of truth lay within nature's mathematics.

Toulouse describes how, when his subject "searches, he often writes a formula automatically in order to awaken some association of ideas... Poincaré proceeds by sudden blows... During the intervals he assumes... that his unconscious continues the work of reflection". The mathematician's manuscripts reflect just this kind of dynamic, associative creativity, darting down formulas and diagrams here and there on any writing surface to hand.

Well might Toulouse express surprise that supremely rational expositions originated from processes that were "seemingly throughout apt for works of pure imagination" in the manner conventionally associated with the arts.

Martin Kemp is in the Department of the History of Art, University of Oxford, 35 Beaumont Street, Oxford OX1 2PG, UK.

e-mail:martin.kemp@trinity.oxford.ac.uk

Quotations from Poincaré and Toulouse are taken from A. I. Miller, Insights of Genius (Copernicus, New York, 1996). 